\title{
Uji Pendahuluan Rancang Bangun Resistivitymeter Berbasis Arduino Nano
}

\author{
Fitri Puspasari, Imam Fahrurrozi, Tika Erna Putri, Estu Muhamad Dwi Admoko
}

Departemen Teknik Elektro dan Informatika, Sekolah Vokasi, Universitas Gadjah Mada, Yogyakarta, Indonesia

\begin{tabular}{l}
\hline Info Artikel \\
\hline Histori Artikel: \\
Diterima: 1 Maret, 2020 \\
Direvisi: 30 Mei, 2020 \\
Diterbitkan: 1 September, 2020 \\
\hline Kata kunci: \\
Resistivitymeter \\
Arus \\
Tegangan \\
Hambatan \\
Arduino Nano \\
\hline Keywords: \\
Resistivitymeter \\
Current \\
Voltage \\
Resistance \\
Arduino Nano \\
\hline
\end{tabular}

\section{Penulis Korespondensi:}

Fitri Puspasari

fitri.puspasari@ugm.ac.id

\begin{abstract}
ABSTRAK
Telah dirancang sebuah prototipe instrumen resistivitymeter berteknologi digital yang memiliki akurasi yang baik. Resistivitymeter merupakan alat yang digunakan dalam eksplorasi, mitigasi bencana, dan mendeteksi pencemaran lingkungan. Metode yang digunakan dalam studi pendahuluan penelitian ini dengan perbandingan langsung menggunakan hambatan berupa resistor. Prinsip kerja dari alat ini adalah dengan mentransmisikan aliran arus listrik. Hasil dari injeksi arus kemudian diukur tegangannya dengan multimeter. Data berupa nilai arus dan tegangan yang nantinya dapat digunakan untuk menetukan nilai resistansi/hambatan. Dari hasil pengujian menggunakan resistor menunjukkan nilai resistansi pada ala tresistivitymeter yang dibuat menunjukkan nilai yang mendekati nilai dari pembacaan multimeter standar, dan masih dibawah batas toleransi dari resistor yang digunakan yaitu sekitar $5 \%$.
\end{abstract}

Has been designed a digital technology resistivity meter instrument that has good accuracy. Resistivity meter is a tool used in exploration, disaster mitigation, and detecting environmental pollution. The method used in the preliminary study of this study with direct comparison using resistors in the form of resistors. The working principle of this tool is to transmit an electric current. The results of the injection current are then measured by a voltage multimeter. Data in the form of current and voltage values which can later be used to determine the resistance value. The results of testing using a resistor shows the resistance value of the resistivity meter that is made shows a value that is close to the value of a standard multimeter reading, and still below the tolerance limit of the resistor used which is around $5 \%$.

\section{PENDAHULUAN}

Resistivitymeter merupakan alat yang digunakan dalam survei geolistrik. Alat ini dapat digunakan untuk eksplorasi, mitigasi bencana, dan mendeteksi pencemaran lingkungan. Pemanfaatan dalam eksplorasi misalnya untuk survei pemetaan potensi air tanah, aspal, batubara, dan mineral lainnya; mitigasi bencana misalnya pada pemetaan potensi longsor; dan untuk mendeteksi pencemaran lingkungan misalnya pencemaran lindi pada air tanah. Eksplorasi yang sangat sering dijumpai adalah pemetaan air tanah dalam (akuifer). Tahapan eksplorasi air tanah ini dilakukan sebelum dilaksanakan pengeboran sumur untuk pencarian air tanah dalam agar dapat diketahui susunan batuan. Hal ini berguna untuk mengetahui ada atau tidaknya lapisan akuifer sumber air tanah dalam. Adapun untuk menentukan letak dan kedalaman akuifer air tanah ialah dengan menggunakan metode geolistrik resistivitas dengan alat resistivitymeter (Telford, dkk., 1990). 
Prinsip kerja resistivitymeter ini dengan mentransmisikan aliran arus listrik ke dalam tanah melalui dua elektroda arus, dan dua elektroda potensial sebagai terminal pengukur potensial yang dihasilkan. nilai potensial yang timbul akibat injeksi arus diukur dengan elektroda potensial. Semua elektroda dalam penggunaannya dipasang pada permukaan tanah (Nejad, 2009).

Pada pengukuran batuan dipengaruhi oleh beberapa faktor antara lain homogenitas batuan, kandungan air dalam batuan, besarnya ruang untuk rembesan fluida (porositas), sifat lapisan pada batuan yang mudah dilalui oleh air tanah (permeabilitas), dan kandungan mineral didalam batuan (Alile, dkk., 2011). Dalam eksplorasi geofisika, metode geolistrik resistivitas mempelajari sifat resistivitas listrik dari lapisan batuan di dalam bumi. Nilai resistivitas dapat dihitung dengan mengetahui besar arus yang ditransmisikan dan besar potensial yang dihasilkan (Arshad, 2007). Penelitian ini bertujuan untuk merancang sebuah instrumen resistivitymeter berharga milyaran dapat di rancang ulang berteknologi digitaldengan harga yang jauh lebih murah dan memiliki akurasi yang baik, yaitu didesain menggunakan aplikasi mikrokontroler arduino Nano.

Arduino Nano (Gambar 1.) termasuk kedalam jenis mikrokontroler yang berbasis AT Mega328 yang memiliki 14 digital pin input / output. Masing-masing dari 14 pin digital pada Nano dapat digunakan sebagai input atau output, menggunakan fungsi pinMode, digitalWrite, dan digitalRead. Setiap pin dapat memberikan atau menerima maksimum $40 \mathrm{~mA}$ dan memiliki resistor pull-up internal 20-50 kOhms. Arduino Nano dapat diaktifkan melalui koneksi Mini-USB, catu daya eksternal 6-20V (pin 30), atau catu daya eksternal 5V (pin 27). Sumber daya dipilih secara otomatis ke sumber tegangan tertinggi (http://www.farnell.com).

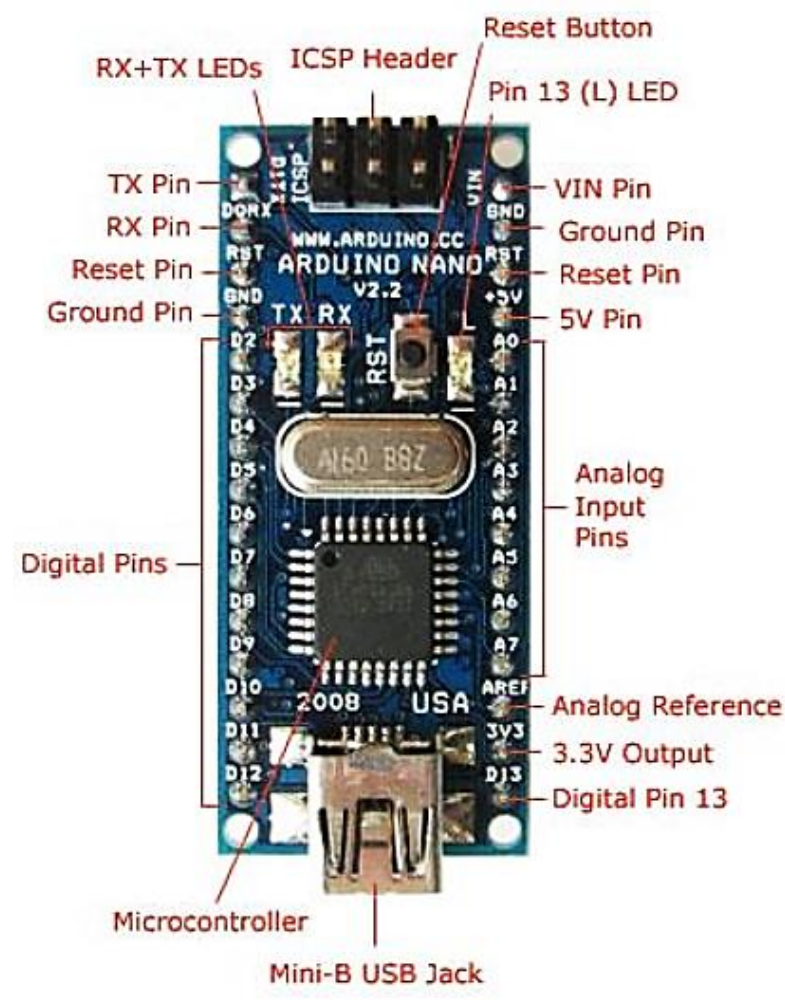

Gambar 1. Arduino Nano (http://www.farnell.com)

Beberapa penelitian terkait perancangan dan pemanfaatan resistivitymeter antara lain James A. Clark dkk. (2011) membangun perangkat instrumen resistivitas kecil, ringan, kuat dan berguna untuk eksplorasi air tanah untuk akuifer dangkal (kurang dari 35 m dalam), Hee-Yoon Ahn dkk. (2012) mengaplikasikan metode resistivitas untuk memantau perubahan nilai tahanan listrik pada perpipaan dalam pembangunan tanggul darurat. Hee Hwan Ryu dkk. (2012) mengembangkan Tunnel Electrical Resistivity Prospecting System (TRPS) untuk mendeteksi kondisi geologi, hidrogeologi, geoteknik 
dengan mengukur serangkaian hambatan listrik dan melakukan analisis kembali. David G. Toll dkk. (2012) mengembangkan sistem pengukuran resistivitas multi-elektroda otomatis sehingga didapatkan akuisisi data yang cepat dan efisien dari pengukuran resistivitas.David G. Toll dkk. (2014) memperkenalkan akuisisi data resistivitas serta software yang fleksibel untuk memperoleh data resistivitas menggunakan pengaturan elektroda yang dapat dikonfigurasi. James A. Clark dkk. (2016) telah mengembangkan instrumen resistivitas sederhana yang dapat dirakit dengan biaya kurang dari $\$ 800$.

\section{METODE}

Penelitian ini merupakan studi pendahuluan dalam pembuatan rancang bangun resistivitymeter. Metode penelititan ini dilakukan dalam dua tahap, yang pertama yaitu pembuatan instrumen pengukur arus dan tegangan. Tahap kedua yaitu pengujian hasil pengukuran dari instrumen pengukur arus dan tegangan terhadap nilai hambatan pada resistor. Berikut adalah diagram alir penelitian (Gambar 2).

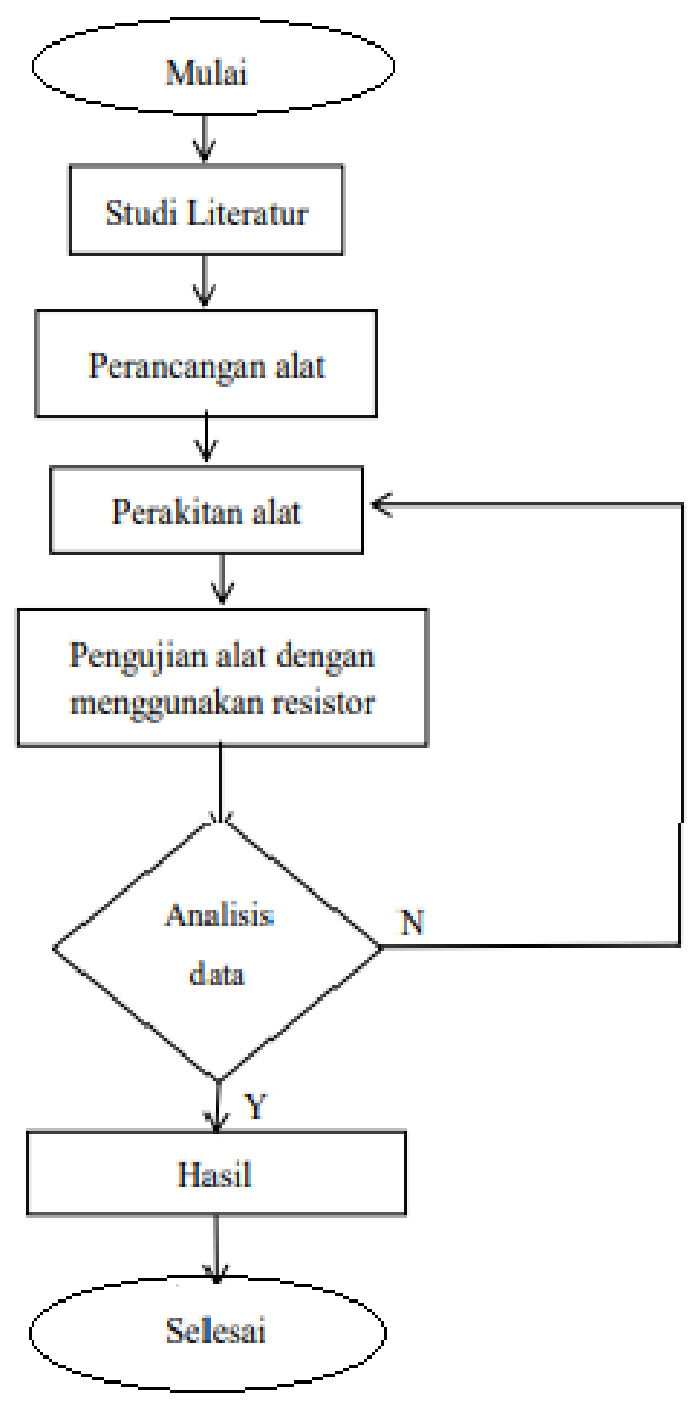

Gambar 2. Diagram Alir Penelitian

Tahap pertama penelitian yaitu membuat instrumen pengukur arus dan tegangan dengan mengacu pada gambar skematik berikut (Gambar 3.). 


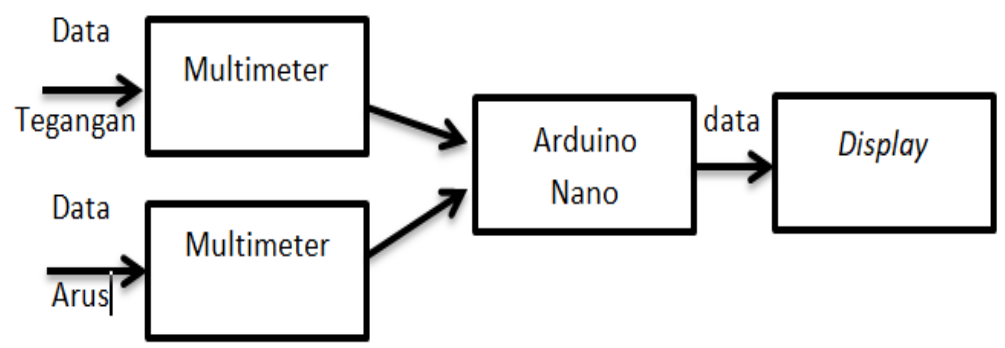

Gambar 3. Skematik instrumen Resistivitymeter

Setelah pembuatan instrumen Resistivitymeter, selanjutnya memasukan program akuisisi data dan dilakukan pengujian. Pengujian dilakukan untuk menghindari kesalahan pada saat proses pengambilan data, sehingga dapat diketahui apakah sistem dapat bekerja dengan baik atau tidak.

Pengujian yang dapat dilakukan antara lain pengujian terhadap pembacaan arus dan teganganlalu dibandingkan dengan hasil pembacaan multimeter standar. Jika hasil pembacaan alat uji resistivitymeter dan multimeter terdapat perbedaan yang jauh, maka akan dilakukan kalibrasi sensor.Pengujian terhadap sistem data logger dan layar penampil, layar penampil yang digunakan berupa LCD yang terdapat pada pengukur arus dan tegangan. Jika terdapat kesalahan, maka akan dilakukan perbaikan program. Terakhir ada peengujian keseluruhan sistem untuk mengetahui tingkat kesesuaian hasil dengan nilai yang diharapkan dengan digunakan multimeter sebagai alat pembanding.

\section{HASIL DAN DISKUSI}

Alat ukur resistivitas tanah skala laboratorium ini terdiri dari lima komponen utama yaitu Arduino Nano, satu buah catu daya, Multimeter Digital berfungsi sebagai pengukur arus dan tegangan, relay, dan konektor (kabel penghubung) Sebagaimana ditunjukkan pada Gambar 4.

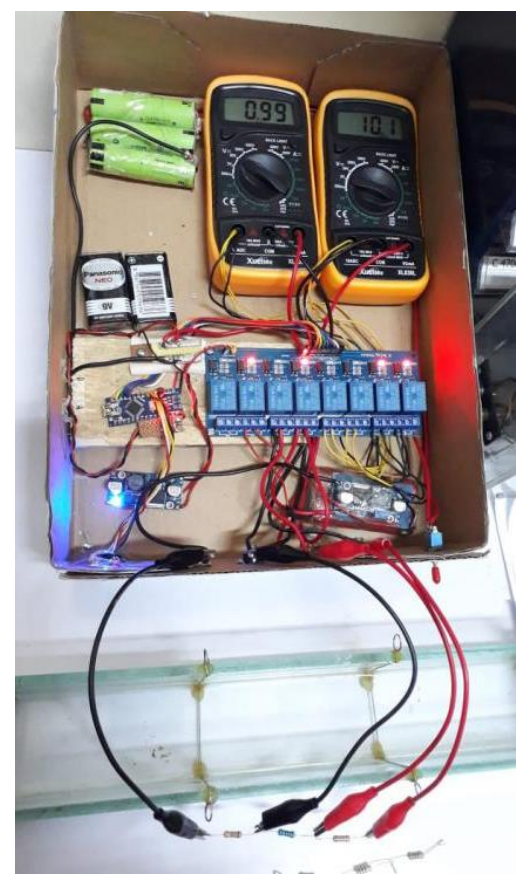

Gambar 4. Rangkaian Instrumen Alat Ukur Resistivitymeter 
Untuk mengetahui kestabilan nilai yang dihasilkan oleh alat ukur resistivitas tanah ini, maka dilakukan uji pembebanan menggunakan Resisitor (Gambar 4). Pada pengujian pembebanan resistor dilakukan pada 3 variasi nilai resistor, diantaranya $200 \Omega, 10 \mathrm{k} \Omega, 100 \mathrm{k} \Omega$. Pengulangan pengukuran pada pengujian setiap resistor dilakukan sebanyak 10 kali untuk menunjukkan tingkat akurasi dari alat yang dibuat. Dari pengujian dibuat dalam bentuk tabel nilai pengukuran terhadap alat dan nilai pengukuran menggunakan Multimeter standar sebagai acuannya. Nilai resistansi/hambatan (R) didapatkan dari perhitungan rumus Hukum Ohm. Berikut adalah hasil pengujian dengan pembebanan resistor (tabel 1, $2,3)$.

Tabel 1 Hasil Perbandingan pembacaan alat resistivitymeter terhadap nilai hambatan Resistor $200 \Omega$

\begin{tabular}{cccc}
\hline No & V (Volt) & I $(\mathbf{m A})$ & $\mathbf{R}(\boldsymbol{\Omega})$ \\
\hline 1 & 0,025 & 0,128 & 195,3125 \\
2 & 0,025 & 0,128 & 195,3125 \\
3 & 0,025 & 0,127 & 196,8504 \\
4 & 0,025 & 0,127 & 196,8504 \\
5 & 0,025 & 0,127 & 196,8504 \\
6 & 0,025 & 0,127 & 196,8504 \\
7 & 0,025 & 0,128 & 195,3125 \\
8 & 0,025 & 0,127 & 196,8504 \\
9 & 0,025 & 0,127 & 196,8504 \\
10 & 0,025 & 0,127 & 196,8504 \\
\hline$X$ & 0,025 & 0,1273 & 196,389 \\
\hline
\end{tabular}

Tabel 1 merupakan data hasil pengujian pembebanan pada variasi resistor dengan nilai $200 \Omega$. pengujian dilakukan dengan 10 kali repeatability. Data yang didapatkan ialah nilai tegangan (V) dan arus (I), dari data tersebut dapat dihitung nilai resistansinya (R). rata-rata nilai yang didapat dari pengukuran resistor $200 \Omega$ adalah $196,389 \Omega$.

Tabel 2 Hasil Perbandingan pembacaan alat resistivitymeter terhadap nilai hambatan Resistor $10 \mathrm{k} \Omega$

\begin{tabular}{cccc}
\hline No & $\mathbf{V}($ Volt $)$ & $\mathbf{I}(\mathbf{m A})$ & $\mathbf{R}(\boldsymbol{\Omega})$ \\
\hline 1 & 1,24 & 0,125 & 9,92 \\
2 & 1,24 & 0,125 & 9,92 \\
3 & 1,24 & 0,126 & 9,84 \\
4 & 1,24 & 0,125 & 9,92 \\
5 & 1,24 & 0,125 & 9,92 \\
6 & 1,24 & 0,125 & 9,92 \\
7 & 1,24 & 0,126 & 9,84 \\
8 & 1,24 & 0,125 & 9,92 \\
9 & 1,24 & 0,126 & 9,84 \\
10 & 1,24 & 0,125 & 9,92 \\
\hline $\mathrm{X}$ & 1,24 & 0,1253 & 9,896 \\
\hline
\end{tabular}

Data uji pembebanan selanjutnya ialah pada variasi resistor $10 \mathrm{k} \Omega$. Data nilai tegangan dan arus yang didapatkan cukup stabil yaitu rata-rata 1,24 Volt untuk nilai tegangan dan 0,1253 miliAmpere untuk nilai rata-rata data arus. Nilai rata-rata resistansi (R) yang didapatkan selisih sekitar $1 \%$ dari nilai gelang warna resistor $10 \mathrm{k} \Omega$, yaitu $9,9 \Omega$. 
Tabel 3 Hasil Perbandingan pembacaan alat resistivitymeter terhadap nilai hambatan Resistor $100 \mathrm{k} \Omega$

\begin{tabular}{cccc}
\hline No & $\mathbf{V}(\mathbf{V o l t})$ & $\mathbf{I}(\mathbf{m A})$ & $\mathbf{R}(\boldsymbol{\Omega})$ \\
\hline 1 & 10,20 & 0,1 & 102 \\
2 & 10,21 & 0,1 & 102,1 \\
3 & 10,20 & 0,1 & 102 \\
4 & 10,20 & 0,1 & 102 \\
5 & 10,20 & 0,1 & 102 \\
6 & 10,20 & 0,1 & 102 \\
7 & 10,20 & 0,1 & 102 \\
8 & 10,20 & 0,1 & 102 \\
9 & 10,20 & 0,1 & 102 \\
10 & 10,20 & 0,1 & 102 \\
\hline $\mathrm{X}$ & 10,201 & 0,1 & 102,01 \\
\hline
\end{tabular}

Hasil uji pembebanan resistor pada variasi nilai $100 \mathrm{k} \Omega$ menunjukkan nilai yang stabil. Selisih nilai hambatan dari gelang resistor dengan nilai yang didapatkan dari uji pembebanan resistor kurang dari 1\%. Keseluruhan data pengujian tiga variasi resistor digambarkan dalam bentuk diagram batang dibawah ini (Gambar 5).

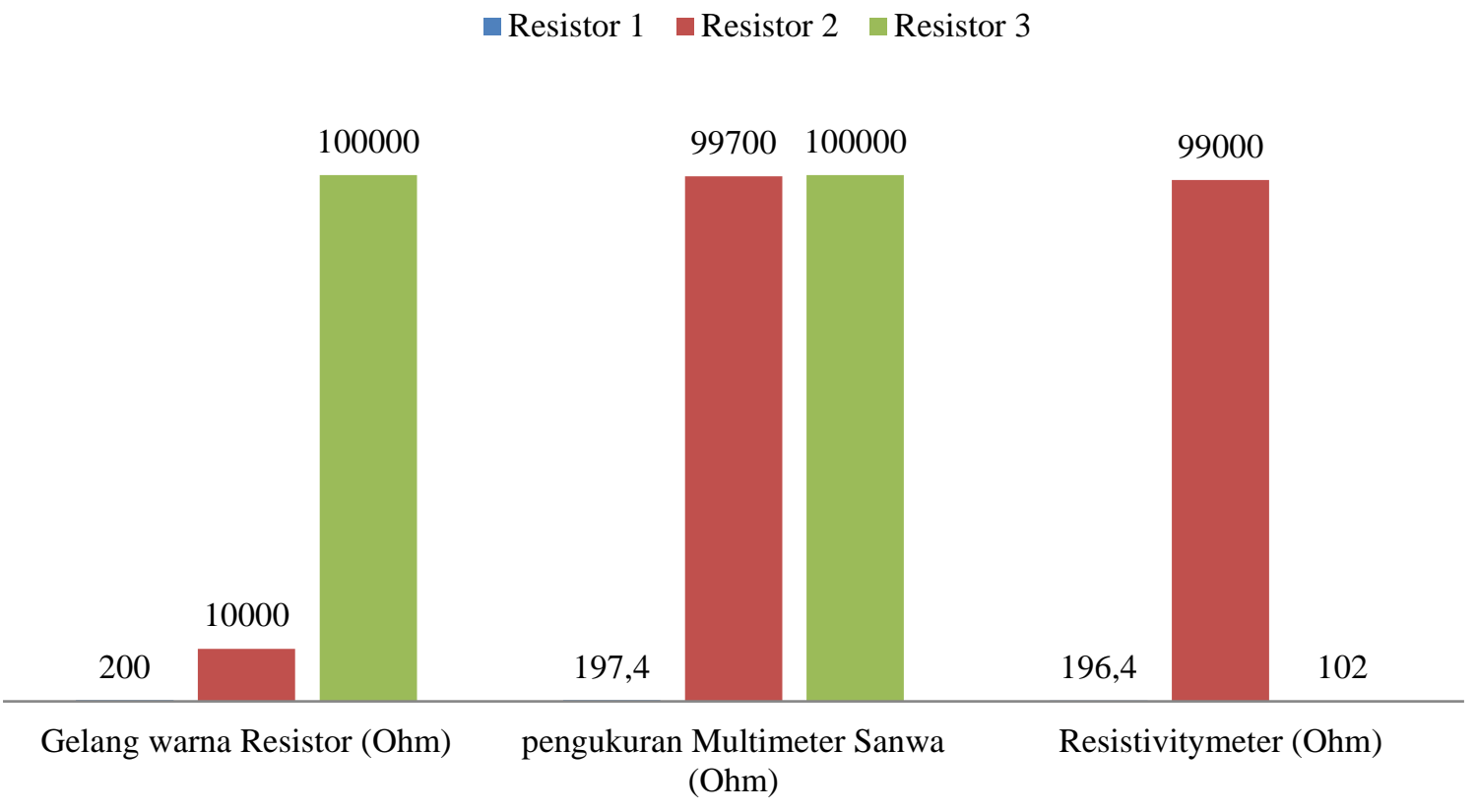

Gambar 5.Hasil Pengukuran Nilai Hambatan Pada resistor

Dari hasil pengujian ini menunjukkan pembacaan nilai pada alat sudah dapat dikatakan stabil. Hal ini dapat dibuktikan dengan perbandingan terhadap hasil pembacaan nilai resistansi pada gelang warna resistor terhadap multimeter standar dan prototipe (Gambar 5). Selain itu, nilai resistansi yang didapatkan tidak terlalu jauh dari nilai toleransi resistor yaitu sekitar 5\% untuk ketiga variasi resistor tersebut. Selisish nilai hambatan yang diperoleh, diperkirakan akibat hambatan dari kabel konektor, adanya daya yang terbuang dan nilai toleransi dari resistor itu sendiri.. Berdasarkan data yang tertuang dalam tabel, dapat diketahui bahwa pembacaan nilai tegangan cenderung konstan, sedangkan pembacaan arus mengikuti besarnya beban yang di berikan. 


\section{KESIMPULAN}

Telah berhasil dirancang prototipe resistivitymeter digital yang mana program dan sistemnya dapat berjalan dengan baik. Hasil pengujian prototipe alat ukur resisitivitas terhadap nilai pembebanan resistor memiliki akurasi yang baik, hal tersebut dapat dilihat dari nilai resistansi yang dihasilkan masih berada dibawah toleransi sebesar 5\%. Saran dari penelitian ini, sebaiknya dilanjutkan dengan membandingkan resistivitymeter yang telah dibuat dengan resistivitymeter yang biasa digunakan untuk pengukuran di lapangan.

\section{DAFTAR PUSTAKA}

Ahn H.Y., Lim., H.D., Ahn H.B, and Kim J.H. (2012). Electrical resistivity monitoring of simulated piping and hydraulic fracturing within a dam structure Applications in Engineering. ISSN 1017-8880 (153-167).

Alile, O.M., Ujuanbi O and Evboumwan, A. (2011). Geoelectric Investigation of Groundwater in Obaretin Lyanomon locality, Edo State, Nigeria. Journal of Geology and Mining Research, 3(1), 13-20.

Arshad M., Cheema J.M and Ahmed S. (2007). Determination of Lithology and Groundwater Quality Using Electrical Resistivity Survey. International Journal of Agriculture and Biology, 09(1), 143 - 146.

Clark, J. A. and Page, R. (2011). Inexpensive geophysical instruments supporting groundwater exploration in developing nations: Journal of Water Resource and Protection, v. 3, no. 10, p. 768-780, doi:10.4236/jwarp.2011.310087

Clark, J.A., Page, R.T., Franklin, R., Miller, N.M., and Morken, M.O. (2016). Appropriate geophysics technology: Inexpensive instruments for water exploration at a local level in developing nations, in Wessel, G.R., and Greenberg, J.K., eds., Geoscience for the Public Good and Global Development: Toward a Sustainable Future: Geological Society of America Special Paper 520, p. 171-181, doi:10.1130/2016.2520(16).

D.G. Toll and Hassan, A. (2012). Development of Automated Multi-electrode Resistivity System for Laboratory Measurements. Istanbul International Geophysical Conference and Oil \& Gas Exhibition: Turkey

D.G. Toll and Hassan, A. (2014). Data Acquisition and Control Software for Automated Resistivity Measurements Information Technology in Geo-Engineering: IOS Press.

Nejad, H.T. (2009). Geoelectric Investigation of the Aquifer Characteristics and Groundwater Potensial in Behbahan Azad University Farm, Khuzestan Province Iran”, Journal of Applied Sciences, 9 (20), 36913698.

Ryu H.H., Cho G.,C., Yang S.D., Shin H.K. (2012). Electrical resistivity monitoring of simulated piping and hydraulic fracturing within a dam structure. Applications in Engineering. ISSN 1017-8880 (179-283).

Telford, W. M., Geldard, L. P. and Sheriff, R. (1990). Applied Geophysics. Cambridge University Press. London.

http://www.farnell.com/datasheets/1682238.pdf 